Volume 19, No 3 International Journal of Radiation Research, July 2021

\title{
Fractionated whole body gamma irradiation potentiate high fat diet- induced intestinal inflammation in Wistar rats
}

\author{
A. Khalil ${ }^{*}$ H. Omran, S. Habeel, F. Alsheikh \\ Department of Radiation Medicine, Human Nutrition Laboratory, Atomic Energy Commission of Syria (AECS), \\ Damascus, Syria
}

\section{- Original article}

*Corresponding authors:
Dr. Ayman Khalil
E-mail:
$\quad$ ascientific13@aec.org.sy
Revised: May 2020
Accepted: June 2020
Int. J. Radiat. Res., July 2021;
19(3): 633-643
DOI: 10.29252/ijrr.19.2.633

\begin{abstract}
Background: In this work, a low-dose rate $(100 \mathrm{mGy} / \mathrm{min}$ of whole body gamma irradiation fractionated (0.5, 1, and 2Gy) was used to study the effects of cumulative doses on the expression of target genes implicated in the intestinal inflammatory process in high fat diet (HFD) wistar rats. Material and Methods: Total RNA was extracted and the expression of target genes was measured in the four intestinal segments (duodenum, jejunum, ileum and colon) of HFD Wistar rats. Results: Our in-vivo results in the four intestinal segments (duodenum, jejunum, ileum, and colon) demonstrated that gamma irradiation exposure in HFD rats amplified the low-grade inflammatory state already induced by HFD. This phenomenon occurs through the induction of pro-inflammatory cytokines mainly the tumor necrosis factor-alpha (TNF $\alpha$ ) and interleukin 6 (IL-6) or via overexpression/increasing of anti-inflammatory response involved interleukin 10 (IL-10) and the growth factor $\beta$ (TGF $\beta$ ) overall the bowel segments. Results suggested that whole body gamma irradiation might have dual roles, first, engraving the inflammatory state already initiated by HFD, and second, an over expressed anti-inflammatory response via anti-inflammatory cytokines mainly IL-10 and TGF $\beta$. Conclusion: The current study clearly demonstrated the important role of the gut in HFD rats during fractionated whole body irradiation (FWBGI) and indicated that TGF $\beta$ and IL-10 may be the target in whole body radiotherapy as a mechanism to recompense for the imbalance between pro-inflammatory and antiinflammatory cytokines.
\end{abstract}

Keywords: Fractionated whole body gamma irradiation (FWBGI), HFD, IL-10, $T G F \beta$, inflammation, intestine.

\section{INTRODUCTION}

Human beings are exposed through our surrounded environment to an array of environmental mediators, which may lead to various health consequences. Irradiation exposure is one of these mediators, which our body exposed through quotidian work, man-made, therapeutic purposes and medical devices. Actually, exposure to ionizing radiation may lead to develop an acute radiation syndrome (ARS). The intestine and bone morrow are from of the first the initial body organs that are involved in ARS (1). The intestinal tissue is well known as the most radiosensitive organs in our body $(2,3)$, mainly the small bowel due to its rapidly proliferating crypt $(3,4)$. However, the colon is the most resistant to radiation injury (5). Independently of the way of a radiation exposure, the intestinal tissue recruits in response to radiation injury a series of signaling pathways involved in inflammation and tissue remodeling $(6,7)$. Radiation-induced inflammatory response could be characterized by the production of several inflammatory mediators such as pro-inflammatory cytokines 
[TNF $\alpha$, interleukin1 $\beta$ (IL-1 $\beta)$, and IL-6], chemokines (IL-8), and growth factors (TGF $\beta$ ) in the micro vascular and mucosal, the recruitment of immune cells, enterocytes and residing cells $(8,9)$.

On the contrary, nutritional consumption is the main way for human survival and developing, in this regard, a dietary contains high energy is the major nutritional habit for many modern nations. Subsequently, this dietary can induce some metabolic disorders ${ }^{10}$ (10) including obesity, type 2 diabetes mellitus, metabolic syndrome and cardiovascular diseases (11,12). Obesity and related health diseases are resulting mainly from feeding on a high fat diet (HFD) and its duration (13). There is substantial evidence that inflammation and oxidative stress are parts of a major mechanism associated with obesity, which is considered as a low-grade of inflammatory state. Moreover, inflammation is recognized as the key link of the diabetes-obesity (14). Inflammation markers such as TNF $\alpha$, C-reactive protein (CRP) and IL-6 are well known to be prominent in obesity (15).

The intestine was selected, since is one of the first organs affected by two environmental factors (dietary that contains high fats and irradiation exposure) as well as due to its physiological role in our body. Therefore, the present study investigates the impact of a fractionated whole body irradiation (in high fat diet Wistar rats) on mRNA expression of some inflammatory mediators in the four fragments of the intestine (duodenum, jejunum, ileum, and colon). Furthermore, the effects of a low-dose rate of different fractionated whole body irradiation doses on the expression of some genes implicated in the inflammatory state deduced by HFD are determined.

This paper aims to evaluate the intestinal inflammatory response due to dietary that contains high fats and the irradiation exposure effect and also, the emergent idea of this work is to figure out and give some new data about the consequences of an irradiation exposure in people that are fed on a high fat diet during radiotherapy or radiotherapy health workers.

\section{MATERIALS AND METHODS}

\section{Animals}

Our study was done following all institutional and national guidelines for the care and use of laboratory animals were obeyed by the Local Scientific and Ethical Committee of the Atomic Energy Commission of Syria (AECS), Damascus, Syria (permit number 2-28/10/2018). All procedures performed in these studies involving animals followed the ethical rules of the Declaration of Helsinki and the internationally accepted principles for the care and use of experimental animals.

Five groups ( $\mathrm{n}=10$ for each group) of adult male Wistar rats weighting $193.5 \mathrm{~g}$ (from Charles Rivers Laboratories, France) were sustained under standard conditions with a $12 \mathrm{~h}$ light/dark cycle having free access to food and water. Normal chow $(n=10)$ and HFD $(n=40)$ diet composition according to $(16,17)$ with some modifications: Normal chow diet (energy content $12 \%$ fat, $26 \%$ protein and $62 \%$ carbohydrates), HFD diet (energy content 74\% fat, $26 \%$ protein, $<1$ carbohydrates). Rats were kept in stainless steel cages $(33 \times 17 \times 40 \mathrm{~cm})$ in an atmosphere of $\sim 50-60 \%$ relative humidity and a temperature of $22 \pm 2{ }^{\circ} \mathrm{C}$.

One HFD group and the group of normal chow diet (NC) served as a standard control for all other irradiated groups.

\section{Irradiation procedure}

During irradiation process, three groups of HFD animals were exposed to different low-dose rate $(100 \mathrm{mGy} / \mathrm{m})$ of fractionated whole-body gamma irradiation $(0.5,1$, and 2 Gy) every three days for about two consecutive months using a gamma ray apparatus (Theratron 80 Canadian design machine, ${ }^{60} \mathrm{Co}$, focal distance of $100 \mathrm{~cm}$ ) (18).

At the end of irradiation treatment, (rats aged about 13 weeks), rats were immolated and the four fragments of bowel (duodenum, ileum, jejunum, and colon) were gathered and stored in $-80^{\circ} \mathrm{C}$. 


\section{Total RNA extraction and real time PCR}

Total RNA was isolated from all gut parts using Roti-phenol reagent (Phenol \Chloroform, $\backslash$ Isomyl $\backslash$ alcohol: $25 \backslash 24 \backslash 1$, ROTH ${ }^{\circledR}$, Germany), and quantified by NanoDrop (NanoDrop technologies, Qiagen, Germany).

Mx3oo5P QPCR systems (Agilent technologies, Germany) was used to quantify the expression of target genes according to the procedure described in our previous work (18). In briefly, the total RNA $(1 \mu \mathrm{g})$ was amplified using the $2 \times$ PCR SyGreenone-step low Rox kit according to the manufacturer's recommendations $\left(\mathrm{ROTH}^{\circledR}\right.$, Germany). PCR was performed with $0.5 \mu \mathrm{M}$ of each primer and with cycling conditions were as follows: $10 \mathrm{~min}$ denaturing at $95^{\circ} \mathrm{C}$, followed by 40 cycles of $30 \mathrm{~s}$ denaturing at $95^{\circ} \mathrm{C}, 30 \mathrm{~s}$ primers annealing at $60{ }^{\circ} \mathrm{C}$ and $30 \mathrm{~s}$ fragment elongation at $72{ }^{\circ} \mathrm{C}$. The melting curve was analyzed with MxPro QPCR Software. Rat TNF $\alpha$, IL1 $\beta$, IL6, CRP, TGF $\beta$ and IL-10 expressions were normalized to $\beta$-actin expression and data quantified by the method of $2^{-\Delta \Delta C t}$.
The primer's efficiency was measured for each primer. Five serial dilutions were used to evaluate the efficiency of studied primers (0.0001, 0.001, 0.01, 0.1 and 1 ) started by $10 \mu \mathrm{l}$ from each primer according the standard curve method. Primer sequence (Eurofins Genomics, Germany) and efficiencies are listed in table 1.

\section{Protein extractions and IL10 protein levels measurement}

Total proteins were isolated from the four intestine segments (duodenum, jejunum, ileum and colon) and IL10 protein levels were determined via same protocols according to previous work $(18,19)$.

\section{Statistical analysis}

Statistical analysis was achieved using the Mann-Whitney test for pair-wise comparisons (Graph Pad Software 5). One-way ANOVA statistical test was used to determine significance differences between groups (statistically significant: $\mathrm{P} \leq 0.05$ means $\pm \mathrm{SD}$ ).

Table 1. Primers used in the current work and their measured efficiency.

\begin{tabular}{|c|c|c|c|}
\hline Gene name & Forward sequence $\left(5^{\prime}-3^{\prime}\right)$ & Reverse sequence $\left(5^{\prime}-3^{\prime}\right)$ & Efficiency \% \\
\hline$\beta$-Actin & 5'-AAGGCCAACCGTGAAAAGAT-3' & 5'-TGGTACGACCAGAGGCATAC-3' & 99 \\
\hline TNF- $\alpha$ & 5'-GGGACAGTGACCTGGACTGT-3' & 5'-TTCGGAAAGCCCATTTGAGT-3' & 97.7 \\
\hline IL-1 $\beta$ & 5'-TCGCTCAGGGTCACAAGAAA-3' & 5'-CATCAGAGGCAAGGAGGAAAA-3' & 96.8 \\
\hline IL-6 & 5'-TCTATACCACTTCACAAGTCGGA-3' & 5'-GAATTGCCATTGCACAACTCTTT-3' & 97.5 \\
\hline CRP & 5'-TTCCCAAGGAGTCAGATACTTCC-3' & 5'-TCAGAGCAGTGTAGAAATGGAGA-3' & 98 \\
\hline TGF- $\beta$ & 5'-TGGAGCAACATGTGGAACTG-3' & 5'-GTCAGCAGCCGGTTACCA-3' & 98.6 \\
\hline IL-10 & 5'-CACAAAGCAGCCTTGCAGAA-3' & 5'-AGAGCAGGCAGGATAGCAGTG-3' & 99 \\
\hline
\end{tabular}

\section{RESULTS}

Results presented in figure 1 demonstrated that, the HFD induced an inflammatory state in all bowel segments of Wistar rats. This inflammatory event is characterized by increasing some pro-inflammatory cytokines mainly $\mathrm{TNF} \alpha$, which increased in all over the bowel by about 5.3-, 2.3-, 3.8-, 2.6- folds, respectively in duodenum (figure $1 \mathrm{~A}$ ), jejunum (figure 1B), ileum (figure 1C), and colon (figure 1D) due to HFD effect. IL-6 is another pro-inflammatory cytokine, which was increased in the jejunum and colon by $\sim 1.5$-, and 3.4-folds, respectively (figures $1 \mathrm{~B}$ and D). IL1 $\beta$ and CRP are other pro-inflammatory cytokines, which were analyzed in this study. In fact, these two cytokines were not detected in the entire bowel except in the duodenum, in which IL1 $\beta$ was not altered by the effect of HFD compared to the normal chow NC (figure 1A), whereas, CRP was not determined in the entire bowel segments. The anti-inflammatory response, mediated by TGF $\beta$ and IL-10, was also analyzed. Results demonstrated that IL-10 was not detected in the upper part of the bowel but the expression of this gene decreased in the lower part mainly in ileum and colon by about 0.3 -fold (figure $1 \mathrm{C}$ and 
D). Comparatively, with TGF $\beta$, the expression of this anti-inflammatory growth factor was significantly decreased in duodenum and ileum by 0.5 - and 0.4 -folds (figure $1 \mathrm{~A}$ and $\mathrm{C}$ ). In contrast, the expression of TGF $\beta$ increased significantly by 2.6 -fold in jejunum (figure $1 \mathrm{~B}$ ) and 3.9-fold in the colon (figure 1D) segment due to HFD effects.

Concerning; the food intake and body weight of HFD Wistar rats in comparison with normal chow, it is noteworthy to notice that no significant data was found in our experiment.

More Results were obtained, when the HFD rats were exposed to a fractionated whole body gamma irradiation (FWBGI), demonstrated that the dose of 12 Gy significantly amplified the expression of some pro-inflammatory cytokines such as IL-6 in duodenum (figure 2C), ileum (figure 4C) and colon (figure 5C) by about 3.4-, 2.1-, and 4-folds. While, TNF $\alpha$ expression was significantly increased in the jejunum, ileum, and colon with 11.7-, 2.5, and 3.4-fold induction, respectively (figures $3 \mathrm{~A}, 4 \mathrm{~A}$ and $5 \mathrm{~A}$ ). The same effect of this dose rate was also remarked with CRP for all bowel segments and the expression of this gene was significantly induced by about 6.8-, 12.6-, 3-, and 7-fold induction as demonstrated, respectively (figures 2D, 3D, 4D and 5D).

Concerning the anti-inflammatory responses to $12 \mathrm{~Gy}$, figures $2 \mathrm{E}, 3 \mathrm{E}$, and $4 \mathrm{E}$ indicate that the expression of TGF $\beta$ significantly increased in duodenum (23.3-fold), jejunum (3.22-fold), and ileum (9.9-fold). However, it was overexpressed in the colon by about 59-fold (figure 5E). On the other hand, the IL-10 was also significantly increased in the gut parts by 15.1-, 1.7-, and 2 -folds in duodenum, jejunum, ileum, and colon (1.6-fold) respectively (figures $2 \mathrm{~F}, 3 \mathrm{~F}, 4 \mathrm{~F}$ and $5 \mathrm{~F})$.

Regarding the dose of 24Gy of WBGI, rat's exposure to such dose rate amplified the pro-inflammatory response mediated by IL6 in the duodenum and ileum parts by about 4.8 -fold and 2.8-fold, respectively (figures $2 \mathrm{C}$ and $4 \mathrm{C}$ ) while IL6 was decreased in jejunum (0.3-fold) by the effect of this dose (figure 3C). Concerning $\mathrm{TNF} \alpha$ pathway, it was noticed that this cytokine was amplified in the jejunum part by about (11-fold) as shown in figure $3 \mathrm{~A}$. The analyzed expressions of TGF $\beta$ and IL10 affected by 24 Gy dose in the bowel showed that TGF $\beta$ was significantly amplified by $\sim 25$-fold in the duodenum (figure 2E) and IL10 was significantly increased all over the bowel segments (figures $2 \mathrm{~F}, 3 \mathrm{~F}, 4 \mathrm{~F}$ and $5 \mathrm{~F}$ ) with an overexpression in the duodenum part by $\sim 28$-fold (figure $2 \mathrm{~F}$ ).

When rats were exposed to 48Gy dose, the pro-inflammatory response was mostly mediated by IL- 6 increase in the entire bowel except in the jejunum (figure 3C). Similarly, a significant induction by the dose of 48Gy dose was observed of pro-inflammatory TNF $\alpha$ gene expression in all bowel segment (figures 2A, 3A, and $4 \mathrm{~A}$ ), expect in the colon, the expression of this cytokine was not altered (figure $5 \mathrm{~A}$ ). The anti-inflammatory response was mediated by IL10 in duodenum (figure 2F) with an over expression 120-fold, jejunum 14.6-fold (figure $3 \mathrm{~F}$ ), ileum 3.2-fold (figure 4F) and in the colon 2.3-fold (figure 5F). The anti-inflammatory response mediated by the TGF $\beta$ pathway was not significantly induced in all bowel segments except in the duodenum; the expression of this growth factor was an over expressed of about 23.4-fold (figure 2E).

Remarkably, CRP was only induced with the 12 Gy dose of WBGI in all bowel segments and was not seen with other dose rates $(24$ and 48Gy). The same is true for IL-1 $\beta$, which was not determined in all bowel segments except in duodenum where its expression was not significantly altered (figure 2D).

Figure 6 demonstrates that the interleukin 10 (IL10) protein levels in the four intestinal segments with the dose of 48Gy. IL-10 has an important role as the major anti-inflammatory cytokines produced by Th2 cells and prevents the production of pro-inflammatory cytokines induced by Th2 cells. However, figure 6 presented an important piece of results and demonstrated the significant increase in the concentration of IL10 protein levels in all bowel segments by $\sim 3.2$-fold versus the control (HFD without irradiation) in duodenum (figure 6A) and 3.6-fold in the jejunum (figure 6B), 1.85-fold in the ileum (figure 6C) and 2.26-fold in the colon (figure 6D).

Int. J. Radiat. Res., Vol. 19 No. 3, July 2021 

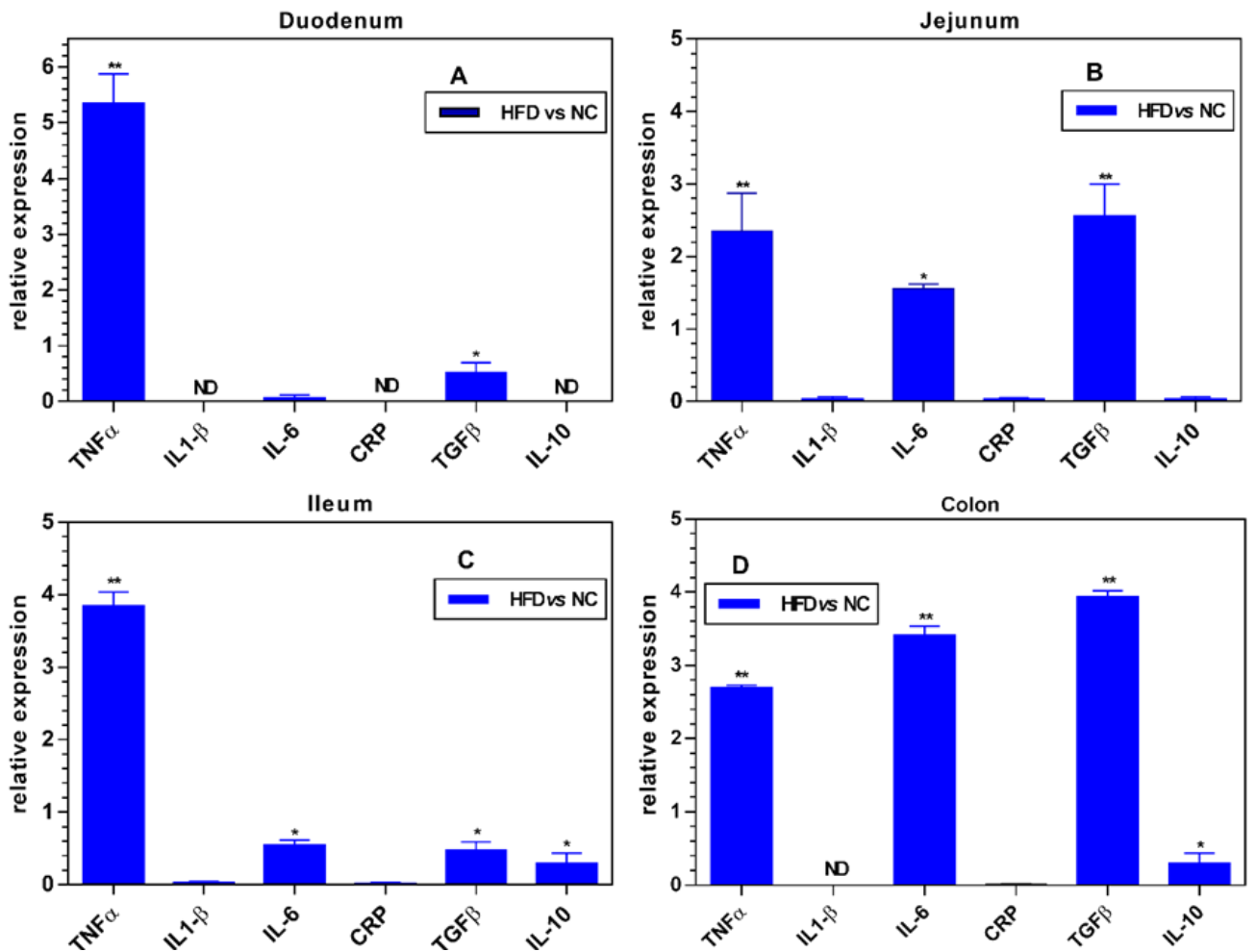

Figure 1. The effects of high-fat diet (HFD) versus normal chow diet mice (NC) on relative gene expression levels of TNF $\alpha$, IL1 $\beta$, IL6, CRP, TGF $\beta$ and IL-10 in the bowel of five-week-old male Wistar rats. A: duodenum, B: jejunum, C: ileum and D: colon. ${ }^{*} p<0.05$, ${ }^{* *} p<0.01,{ }^{* * *} p<0.001$. ND is not determined.

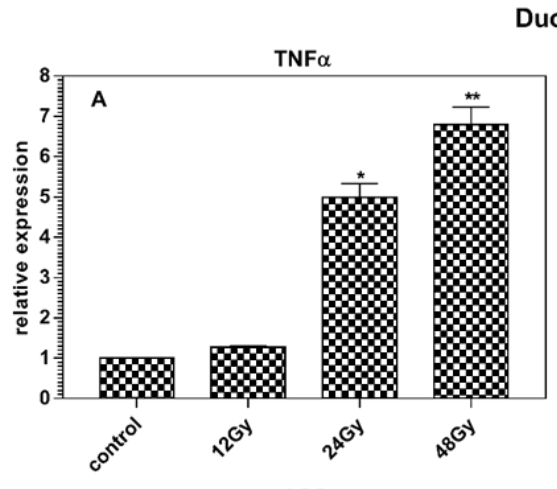

uodenum
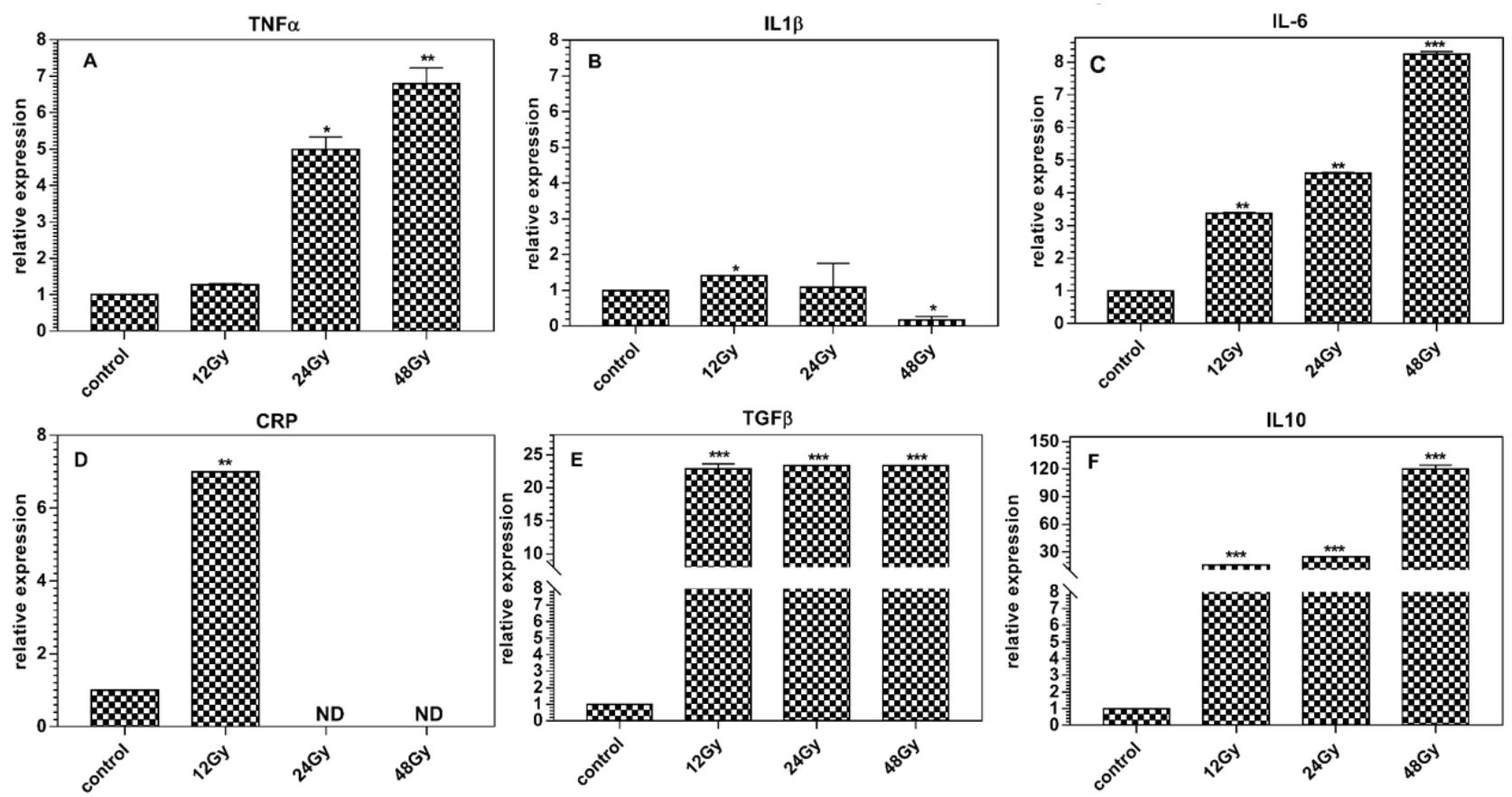

Figure 2. Effects of fractionated whole body gamma irradiation $(12,24$ and $48 \mathrm{~Gy})$ at a low-dose rate of $100 \mathrm{mGy} / \mathrm{min}$ on relative gene expression levels in the bowel duodenum of high-fat diet (HFD) of 13-week-male Wistar rats compared with the control group. A: TNF $\alpha$, B: IL1 $\beta$, C: IL6, D: CRP, E: TGF $\beta$ and F: IL10. ${ }^{*} p<0.05,{ }^{* *} p<0.01,{ }^{* * *} p<0.001$. ND is not determined. 

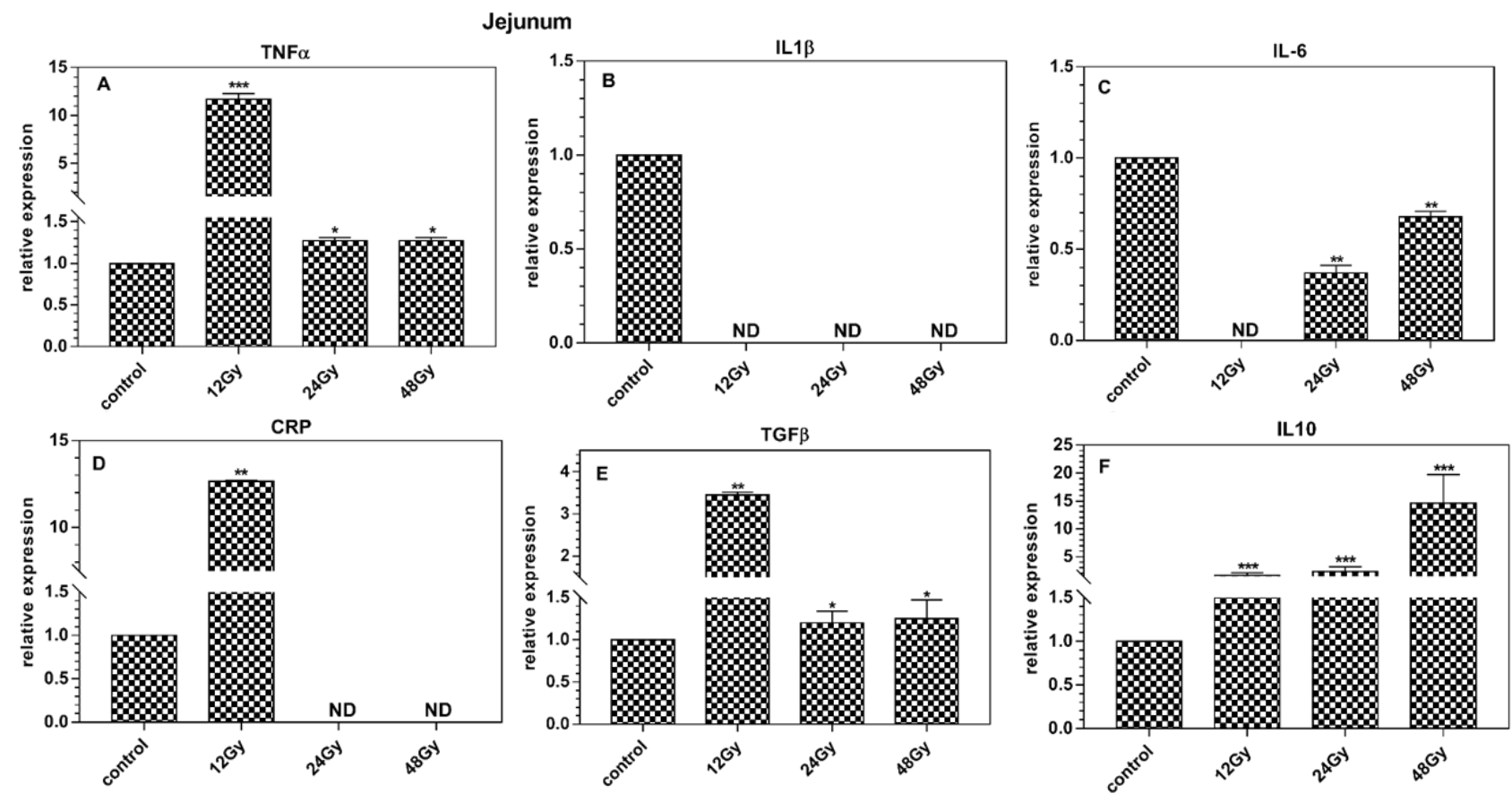

Figure 3. Effects of fractionated whole body gamma irradiation $(12,24$ and $48 \mathrm{~Gy})$ at a low-dose rate of $100 \mathrm{mGy} / \mathrm{min}$ on relative gene expression levels in the bowel jejunum of high-fat diet (HFD) of 13-week-male Wistar rats compared with the control group. A: TNF $\alpha, B:$ IL1 $\beta, C:$ IL6, D: CRP, E: TGF $\beta$ and F: IL10. ${ }^{*} p<0.05,{ }^{* *} p<0.01,{ }^{* * *} p<0.001$. ND is not determined

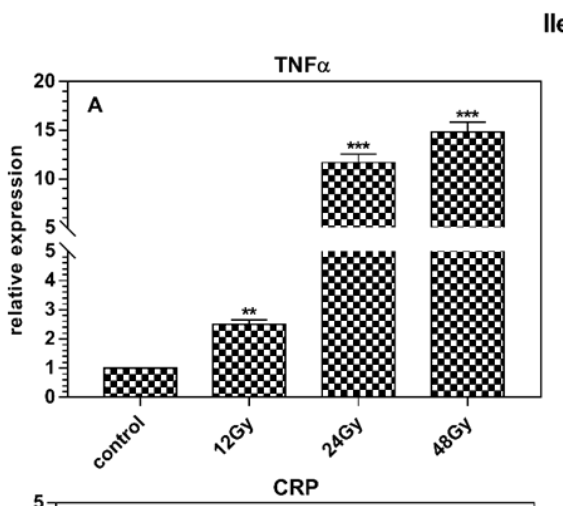

lleum
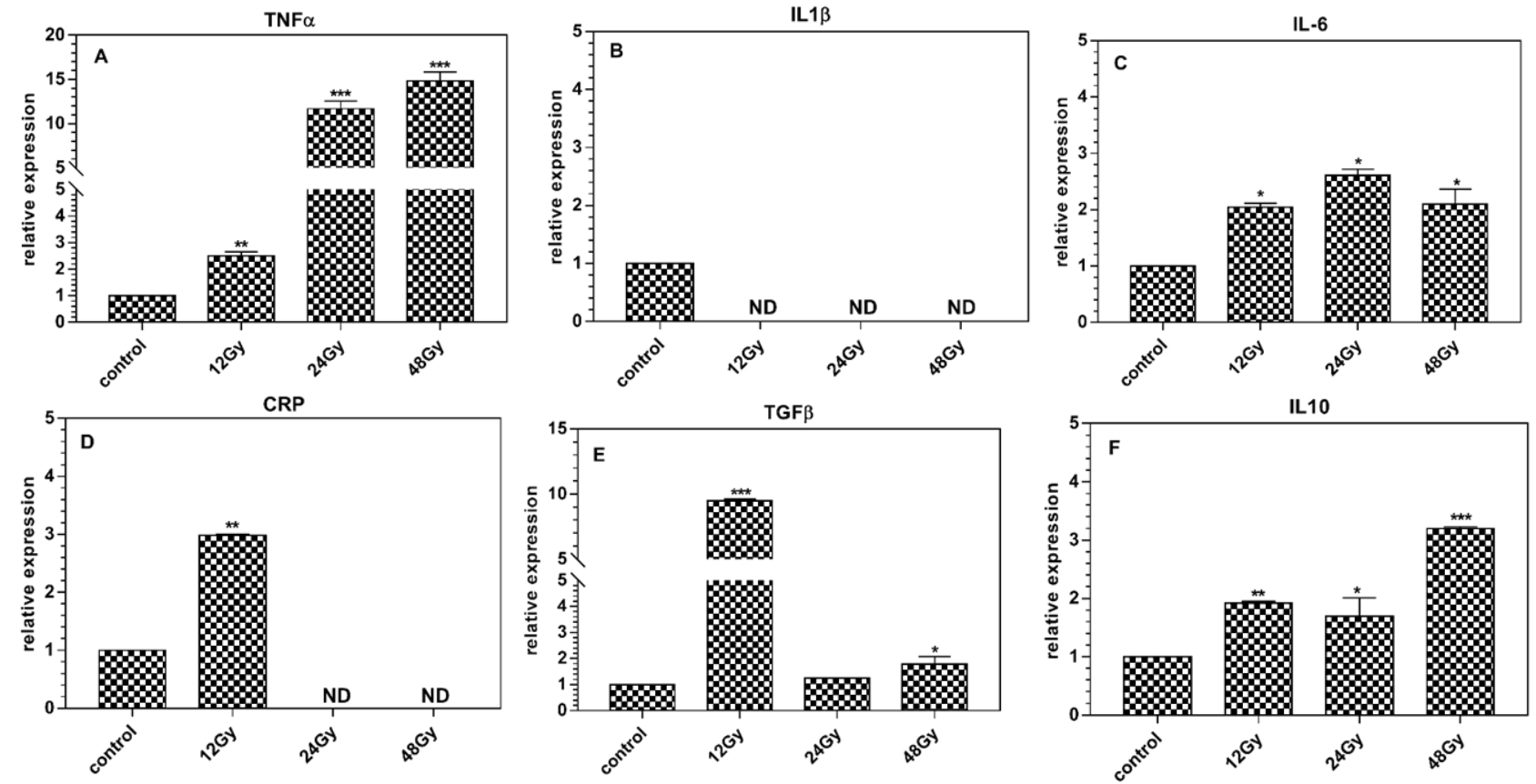

Figure 4. Effects of fractionated whole body gamma irradiation (12, 24 and $48 \mathrm{~Gy}$ ) at a low-dose rate of $100 \mathrm{mGy} / \mathrm{min}$ on relative gene expression levels in the bowel ileum of high-fat diet (HFD) of 13-week-male Wistar rats compared with the control group.

A: TNF $\alpha, B:$ IL $\beta, C:$ IL6, D: CRP, E: TGF $\beta$ and F: IL10. ${ }^{*} p<0.05,{ }^{* *} p<0.01,{ }^{* * *} p<0.001$. ND is not determined 

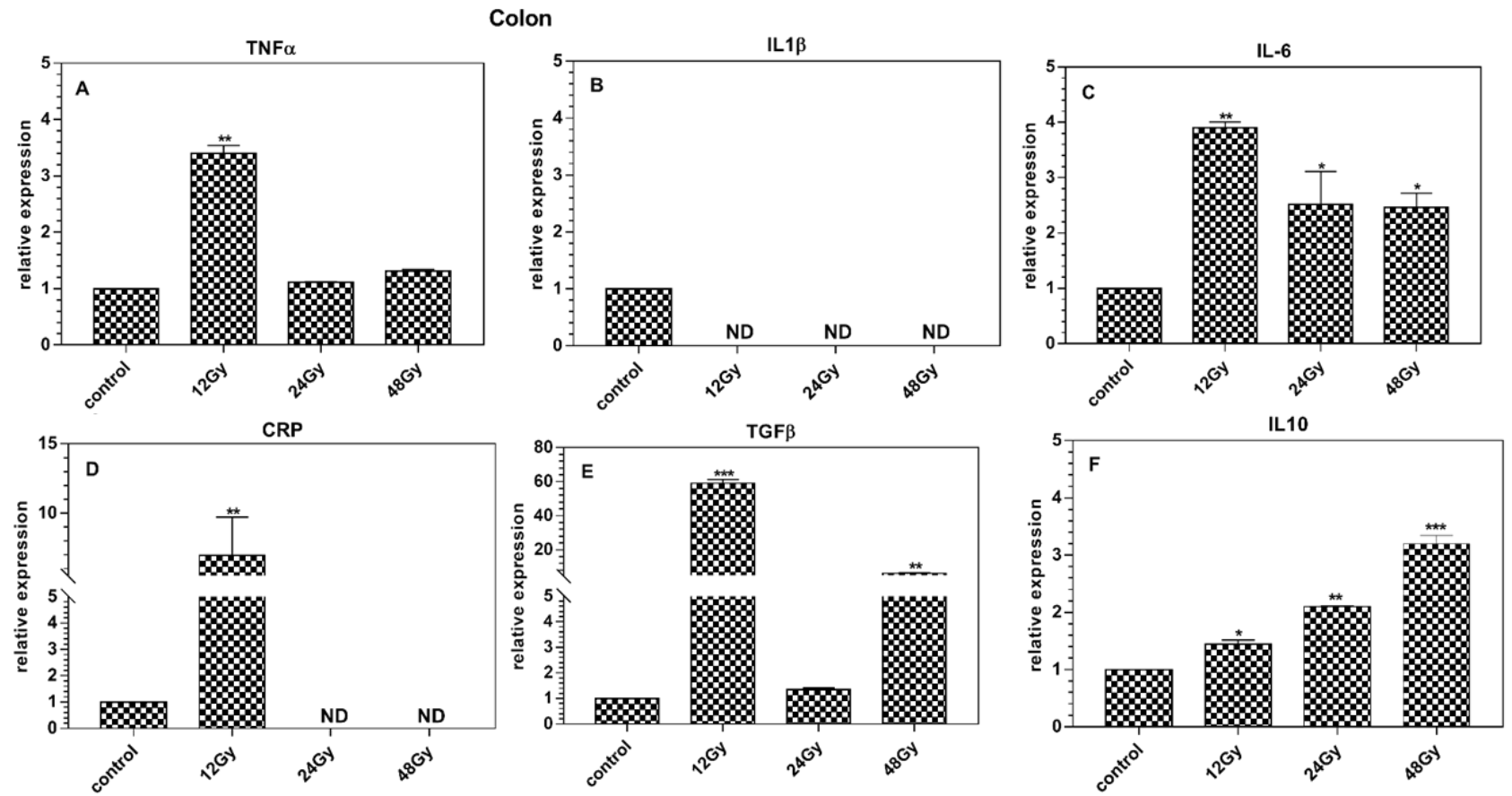

Figure 5. Effects of fractionated whole body gamma irradiation $(12,24$ and $48 \mathrm{~Gy})$ at a low-dose rate of $100 \mathrm{mGy} / \mathrm{min}$ on relative gene expression levels in the bowel colon of high-fat diet (HFD) of 13-week-male Wistar rats compared with the control group. A: TNF $\alpha$, B: IL1 $\beta$, C: IL6, D: CRP, E: TGF $\beta$ and F: IL10. ${ }^{*} p<0.05,{ }^{* *} p<0.01,{ }^{* * *} p<0.001$. ND is not determined
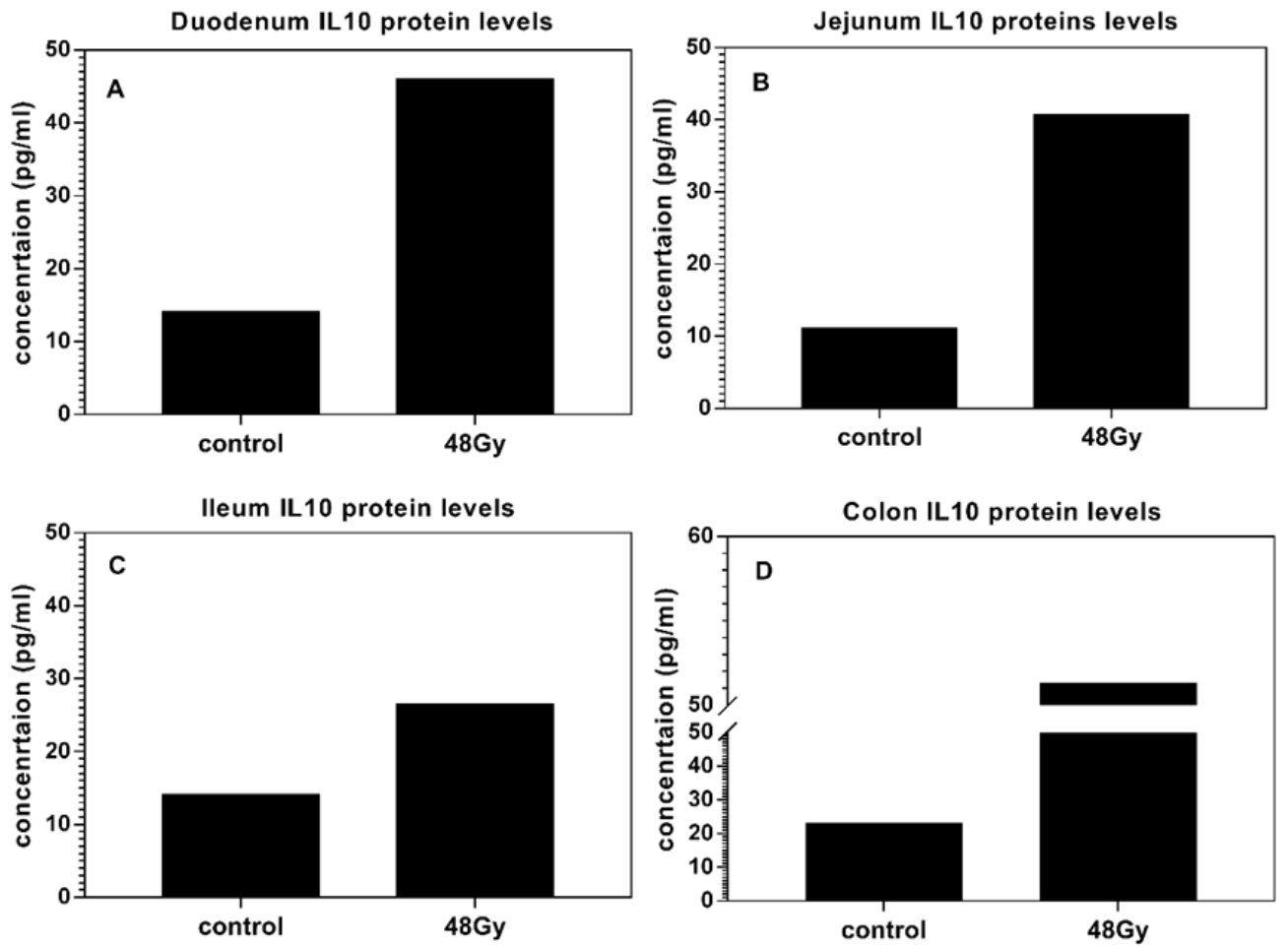

Figure 6. Effects of fractionated whole body gamma irradiation ( $48 \mathrm{~Gy}$ ) at a low-dose rate of $100 \mathrm{mGy} / \mathrm{min}$ on protein levels of interleukin 10 (IL-10) in the bowel of high-fat diet (HFD) of 13-week-male Wistar rats compared with the control group.

A: duodenum, B: jejunum, D: ileum and C: colon. 


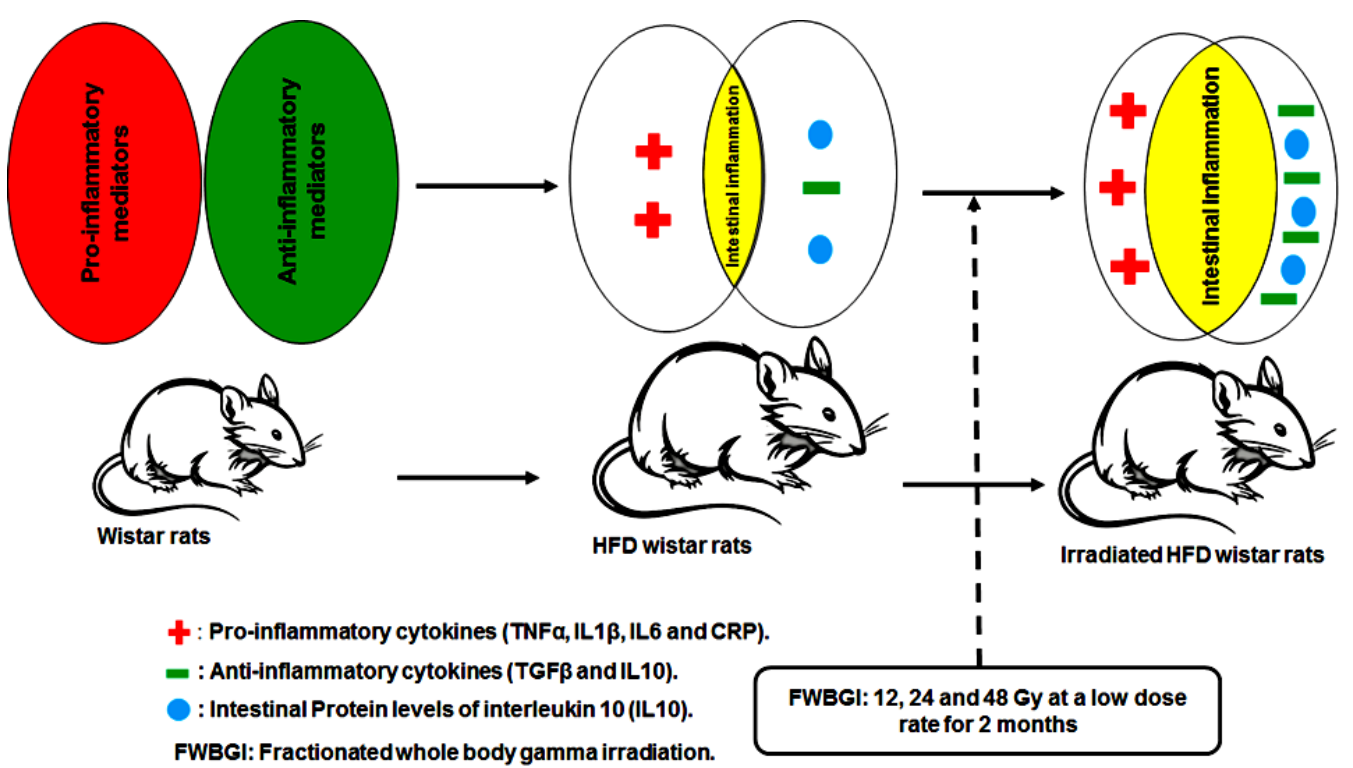

Figure 7. A graphical abstract concludes the main finding in this study: Fractionated whole body gamma irradiation (FWBGI) potentiate the intestinal inflammation by amplification of pro/anti-inflammatory cytokines (mRNA and IL-10 protein levels) when HFD Wistar rats exposed to 24 fractions of WBGI at a low dose rat of $100 \mathrm{mGy} / \mathrm{min}(0.5,1$ and $2 \mathrm{~Gy})$ three times a week, respectively.

\section{DISCUSSION}

It is well established in the literature that HFD is able to induce an obesity state in both human and rats $(13,20-22)$. In fact, the obesity itself is a low-grade inflammatory state that could develop to related diseases as a result of amplification of many factors such as cytokines. Since the bowel has a primary contact with food, the expression of genes implicated in the inflammatory response in the four bowel fragments (duodenum, jejunum, ileum, and colon) after fractionated whole body irradiation in HFD Wistar rats were investigated.

In fact, our results (figure 1) are in consistent with previous works indicating that HFD is causing a state of inflammatory response in HFD mice by the amplification of similar cytokines (23). In general, HFD animal models induced an inflammatory state mediated by cytokines are well known in the related literature to increase some pro-inflammatory markers and to inhibit the anti-inflammatory ones (23-25).

Overall, results indicate that FWBGI had a dual role in the inflammatory state already induced by HFD in Wistar rat's bowel (figures 2, 3,4 and 5). From one hand, pro-inflammatory cytokines such as TNF $\alpha$, IL- 6 and CRP were 640 amplified by the irradiation exposure. It is known that, irradiation exposure rapidly increase pro-inflammatory cytokines such as TNF $\alpha$ and IL-1 $\beta$, which have been associated to both lung and brain damage (26-29). Additionally, IL-6 increased in rat serum after total and localized body irradiation (29). More recent studies have been shown that the over expression of TNF $\alpha$, IL-1 $\beta$ after whole rat brain irradiation has been noticed (30). A single abdominal dose of gamma irradiation (10 Gy) induced an increase of TNF $\alpha$, IL- 6 and IL-1 $\beta$ mRNA levels in the rats' ileal muscularis layer (31), and that observation is exactly consistent with our reported study. In fact, this amplification of pro-inflammatory cytokines reported in our study can be supposed by radiation-induced NF-kB and AP-1 interactions, which is indeed leading to obtain inducible expression of such pro-inflammatory cytokines $(32,33)$. From the other hand, the effect of irradiation exposure was not limited to increase pro-inflammatory cytokines but interestingly induced an over expression of an antiinflammatory responses mediated mainly in our results by IL-10 in duodenum, and jejunum (figures $2 \mathrm{~F}$ and $3 \mathrm{~F}$ ). Also, a significant increase in ileum and colon is observed in figures $4 \mathrm{~F}$ and Int. J. Radiat. Res., Vol. 19 No. 3, July 2021 
5F. In addition, TGF $\beta$ in the duodenum of HFD rats was overexpressed by the effect of all FWBGI used doses (figure 2E) which is similar to a study that showed an increase in TGF $\beta$ levels after fractionated irradiation in mice (34). This result is of a great importance and gives a portative role during FWBGI in the intestine of HFD Wistar rats. In fact, this latter role of irradiation exposure agrees by other studies, which reported some anti-inflammatory cytokines induction such as mainly a significant increase of IL-10 in ovalbumin-immunized mice exposed to 0.5Gy dose (35). Similarly, the down regulation of pro-inflammatory cytokines (IL-6 and IL-1 $\beta$ ) was observed, after $4 \mathrm{~h}$ of $2 \mathrm{~Gy}$ of total body irradiation in macrophages (36); which is also in good agreement with our findings: TNF $\alpha$ was not changed in jejunum, and colon by the dose of 24, and 48Gy of gamma exposure (figures $3 \mathrm{~A}$ and $5 \mathrm{~A}$ ). Similarly, our results are also in good agreement with another study, which reported an increase in IL-10 in both naïve, and activated splenocytes after irradiation (37). Recent study from our laboratory demonstrated with that, same doses in Wistar rats that the FWBGI may has a protective role in the type 2 diabetes mellitus by the induction of anti-diabetic agent of Glucagon like peptide-1 (GLP-1) and Glucagon like peptide-1 receptor (GLP-1R) $(37,38)$, and this latest result support our finding in this work that FWBGI induce anti-inflammatory mediators overall the bowel.

Actually, radiation-induced inflammation of the gastrointestinal tract is one of the critical causes for systemic complications following irradiation exposure, which may lead to multiple organ failure $(6,39,40)$. Our results demonstrated that intestinal inflammation during FWBGI in HFD rats might play an important role in inflammatory reaction via the amplification of mRNA and protein level expressions of some cytokines, which characterized the inflammation response versus irradiation exposure (figure 6).

Notably, in contrast to what we expected. The results of this work were surprised, especially on the protein levels of ant-inflammatory cytokine IL10, which supported the already obtained results on the mRNA levels. In fact, this results presented in Figure 6 definitely supported the protective role of FWBGI by this animal model under our conditions against inflammatory enlargement by the induction of anti-inflammatory gene, IL10. The important of this anti-inflammatory cytokine is due to its suppressing inflammatory responses (41, 42), down regulating the synthesis of $\mathrm{TNF} \alpha$ and IL-1 $\beta$ and by the fact that IL-10 knockout mice develop gastrointestinal inflammation (43).

Finally, the ionization ration including FWBGI is a complicated process that initiates several other molecules cascades related to inflammatory process rather than studies in this work counting many other cytokines and cytokine receptors, which are important to furthermore study, especially those molecules who have radio therapeutic action.

\section{CONCLUSIONS}

The intestine, an immunologically active organ is likely to play an active role in the systemic radiation response. These findings may be important for future development of strategies to moderate intestinal radiation, particularly in the modulating inflammatory reaction in the bowel, which have significant effects on the rest of the body, particularly via the of IL-10 and TGF $\beta$ overexpression as result of irradiation exposure in HFD rats.

However, the main results in this study are summarized in figure 7 , which demonstrate the important role of the intestine during FWBGI exposure in the inflammatory process in HFD Wistar rats.

\section{ACKNOWLEDGMENT}

The authors would like to express their deep appreciation to Prof. Ibrahim Othman, the director general of the Atomic Energy Commission of Syria (AECS). Thanks to Dr. Mohammed A Bakir, head of the radiation medicine department for his help and support throughout the period of this research. Thanks are also extended to Dr. Abdul Wahab Allaf for his 
efforts in English editing.

Conflicts of interest: Declared none.

\section{REFERENCES}

1. Grammaticos P, Giannoula E, Fountos GP (2013) Acute radiation syndrome and chronic radiation syndrome. Hell $J$ Nucl Med, 16: 56-9.

2. Keefe DM, Gibson RJ, Hauer-Jensen M (2004) Gastrointestinal mucositis. Semin Oncol Nurs, 20: 38-47.

3. Hauer-Jensen M, Wang J, Boerma M, Fu Q, Denham JW (2007) Radiation damage to the gastrointestinal tract: mechanisms, diagnosis, and management. BMJ Support Palliat Care, 1: 23-9.

4. Hauer-Jensen, $M(1990)$ Late radiation injury of the small intestine. Clinical, pathophysiologic and radiobiologic aspects. Acta Oncologica, 29: 401-15.

5. Thiagarajah JR, Gourmelon P, Griffiths NM, Lebrun F, Naftalin RJ, Pedley KC (2000) Radiation induced cytochrome $\mathrm{c}$ release causes loss of rat colonic fluid absorption by damage to crypts and pericryptal myofibroblasts. Gut, 47: 675-84.

6. François A, Milliat F, Guipaud O, Benderitter M (2013) Inflammation and immunity in radiation damage to the gut mucosa. Biomed Res Int, 2013: 123241.

7. Leppkes $M$, Roulis M, Neurath MF, Kollias G, Becker C (2014) Pleiotropic functions of TNFa in the regulation of the intestinal epithelial response to inflammation. Int Immunol, 26: 509-15.

8. Polistena A, Johnson LB, Ohiami-Masseron S, et al. (2008) Local radiotherapy of exposed murine small bowel: apoptosis and inflammation. BMC Surgery, 8: 1-1.

9. Ong, ZY, Gibson, RJ, Bowenm, JM, Stringer AM, Darby JM, Logan RM, Yeoh AS, Keefe DM (2010) Pro-inflammatory cytokines play a key role in the development of radiotherapy-induced gastrointestinal mucositis. Radiat Oncol, 5: 1 22.

10. Buettner, R, Parhofer, KG, Woenckhaus, M, Wrede, CE, Kunz-Schughart, LA, Schölmerich, J, Bollheimer, LC (2006) Defining high-fat-diet rat models: metabolic and molecular effects of different fat types. J Mol Endocrinol, 3: 485-501.

11. Lichtenstein AH, Appel LJ, Brands M, Carnethon M, Daniels S, Franch HA, Franklin B, Kris-Etherton P, Harris WS, Howard B, et al. (2006) Diet and lifestyle recommendations revision. A scientific statement from the American Heart Association Nutrition Committee. Circulation, 114: 82-96.

12. US Department of Agriculture and US Department of Health and Human Services (2010) Dietary Guidelines for Americans, 7th ed.; U.S. Government Printing Office: Washington, DC, USA.

13. Ghibaudi L, Cook J, Farley C, van Heek M, Hwa JJ (2002) Fat intake affects adiposity, Comorbidityfactors and energy metabolism of sprague-dawley rats. Obesity Res, 10:
956-963.

14. Hotamisligil GS and Spiegelman BM (1994) Tumor necrosis factor alpha: a key component of the obesity-diabetes link. Diabetes, 43: 1271-1278.

15. Burke, AP, Tracy, RP, Kolodgie, F, Malcom, GT, Zieske, A, Kutys, R (2002) Elevated C-reactive protein values andatherosclerosis in sudden coronary death: Associationwith different pathologies. Circulation, 105: 2019-2023.

16. Auberval N, Dal $S$, Bietiger $W$, Pinget $M$, Jeandidier $N$, Maillard-Pedracini E, Schini-Kerth V, Sigrist S (2014) Metabolic and oxidative stress markers in Wistar rats after 2 months on a high-fat diet. Diabetol Metab Syndr, 6: 130.

17. Leduc-Gaudet J-P, Reynaud $O$, Chabot F, Mercier J, Andrich DE, St-Pierre DH, Gouspillou G (2018) The impact of a short-term high-fat diet on mitochondrial respiration, reactive oxygen species production, and dynamics in oxidative and glycolytic skeletal muscles of young rats. Physiol Rep, 6(4): e13548.

18. Khalil A, Omran H, Alsheikh F (2018) Balance of pro- and anti-inflammatory cytokines in livers of high fat diet rats exposed to fractionated gamma irradiation. BMC Res Notes, 11: 741.

19. Khalil A, Al-Massarani G, Aljapawe A, Ekhtiar A, Bakir MA (2020) Resveratrol Modulates the Inflammatory Profile of Immune Responses and Circulating Endothelial Cells' (CECs') Population During Acute Whole Body Gamma Irradiation. Front Pharmacol, 11: 528400.

20. Boozer CN, Schoenbach G, Atkinson RL (1995) Dietary fat and adiposity-a dose-response relationship in adult male rats fed isocalorically. Am J Physiol Endocrinol Metab, 268: E546-E550.

21. Hill JO, Melanson EL, Wyatt, HT (2000) Dietary fat intake and regulation of energy balance: implications for obesity. J Nutr, 130: 284S-288S.

22. Jequier E (2002) Pathways to obesity. Int J Obes, 26: S12S17.

23. Khalil A, Villard PH, Dao MA, Burcelin R, Champion $S$, Fouchier F, Savouret JF, Barra Y, Seree E (2010) Polycyclic aromatic hydrocarbons potentiate high-fat diet effects on intestinal inflammation. Toxicol Lett, 196: 161-7.

24. Kerstin S, Diego P-T, Gayathri A, Anja B, Randy JS, Matthias HT, Daniel RD, Paul TP (2012) High-fat-diet-induced obesity causes an inflammatory and tumor-promoting microenvironment in the rat kidney. Dis Model Mech, 5: 627-635.

25. Van der Heijden RA, Sheedfar F, Morrison MC, Hommelberg PP, Kor D, Kloosterhuis NJ, Heeringa P (2015) High-fat diet induced obesity primes inflammation in adipose tissue prior to liver in C57BL/6j mice. Albany NY, 7: 256-267.

26. Hong JH, Chiang CS, Campbell IL, Sun JR, Withers HR, McBride WH (1995) Induction of acute phase gene expression by brain irradiation. Int J Radiat Oncol Biol Phys, 33: 619-626.

27. Hong JH, Chiang CS, Tsao CY, Lin PY, McBride WH, Wu CJ (1999) Rapid induction of cytokine gene expression in the lung after single and fractionated doses of radiation. Int $\mathrm{J}$ Rad Biol, 75: 1421-1427.

28. Gaber MW, Sabek OM, Fukatsu K, Wilcox HG, Kiani MF, Merchant TE (2003) Differences in ICAM-1 and TNF-alpha Int. J. Radiat. Res., Vol. 19 No. 3, July 2021 
expression between large single fraction and fractionated irradiation in mouse brain. Int J Rad Biol, 79: 359-366.

29. Han SK, Song JY, Yun YS, Yi SY (2006) Effect of gamma radiation on cytokine expression and cytokine-receptor mediated STAT activation. Int J Rad Biol, 82: 686-97.

30. Haveman J, Geerdink AG, Rodermond HM (1998) TNF $\alpha$, IL$1 \beta$ and IL- 6 in circulating blood after total-body and localized irradiation in rats. Oncol Rep, 5: 679-683.

31. Lee WH, Sonntag WE, Mitschelen M, Yan H, Lee YW (2010) Irradiation induces regionally specific alterations in proinflammatory environments in rat brain. Int J Rad Biol, 86: 132-144.

32. Linard C, Ropenga A, Vozenin-Brotons MC, Chapel A, Mathe D (2003) Abdominal irradiation increases inflammatory cytokine expression and activates NF-kappa B in rat ileal muscularis layer. Am J Physiol Gastrointest Liver Physiol, 285: G556-G565.

33. Park HR, Jo SK, Yu DK, Jung U (2013) Fractionated irradiations lead to chronic allergic airway inflammation through increasing the influx of macrophages. Inflamm Res, 62: 2736.

34. Beetz A, Peter RU, Oppel T, Kaffenberger W, Rupec RA,Van Beuningen D, Kind P, Messer G (2000) NF-kB and AP-1are responsible for inducibility of the IL- 6 promoter by ionizingradiation in HeLa cells. Int J Radiat Bio, 176: 1443-1453.

35. Nakatsukasa H, Tsukimoto M, Tokunaga A, Kojima S (2010) Repeated gamma irradiation attenuates collagen-induced arthritis via up-regulation of regulatory cells but not by damaging lymphocytes directly. Radiat Res, 174: 313-324.

36. Hosoi Y, Miyachi H, Matsumoto Y, Enomoto A, Nakagawa
K, Suzuki N, Ono T (2001) Induction of interleukin-1 $\beta$ and interleukin- 6 mRNA by low doses of ionizing radiation in macrophages. Int J Cancer, 96: 270-276.

37. Khalil A and Omran H (2018) The role of gut in type 2 diabetes mellitus during whole body gamma irradiation in high-fat diet Wistar rats. Int J Radiat Biol, 94: 137-149.

38. Monti P, Wysocki J, van der Meeren A, Griffiths NM (2005) The contribution of radiation-induced injury to the gastrointestinal tract in the development of multi-organ dysfunction syndrome or failure. Brit J Radiol, 27: 89-94.

39. Van der Meeren A, Monti P, Vandamme M, Squiban C, Wysocki, J, Griffiths N (2005) Abdominal radiation exposure elicits inflammatory responses and abscopal effects in the lungs of mice. Radiat Res, 163: 144-152.

40. François A, Aigueperse J, Gourmelon P, Macnaughton WK, Griffiths NM (1998) Exposure to ionizing radiation modifies neurally evoked electrolyte transport and some inflammatory responses in rat colon in-vitro. Int J Radiat Biol, 73: 93-101.

41. Chen ML, Wang FH, Lee PK, Lin CM (2001) Interleukin-10induced $\mathrm{T}$ cell unresponsiveness can be reversed by dendritic cell stimulation. Immunol Lett, 75: 91-96.

42. Cassatella MA, Meda L, Gasperini S, Calzetti F, Bonora S (1994) Interleukin 10 (IL-10) upregulates IL-1 receptor antagonist production from lipopolysaccharide-stimulated humanpolymorphonuclear leucocytes by delaying mRNA degradation. J Exp Med, 179: 1695-1699.

43. Kuhn R, Lohler J, Rennick D, Rajewsky K, Muller W (1993) Interleukin-10 deficient mice develop chronic enterocolitis. Cell, 75: 263-274. 
